\title{
Do non-verbal number systems shape grammar? Numerical cognition and Number morphology compared
}

\author{
Franzon, Francesca ; Zanini, Chiara ; Rugani, Rosa
}

\begin{abstract}
Number morphology (e.g., singular vs. plural) is a part of the grammar that captures numerical information. Some languages have morphological Number values, which express few (paucal), two (dual), three (trial) and sometimes (possibly) four (quadral). Interestingly, the limit of the attested morphological Number values matches the limit of non-verbal numerical cognition. The latter is based on two systems, one estimating approximate numerosities and the other computing exact numerosities up to three or four. We compared the literature on nonverbal number systems with data on Number morphology from 218 languages. Our observations suggest that nonverbal numerical cognition is reflected as a core part of language.
\end{abstract}

DOI: https://doi.org/10.1111/mila.12183

Posted at the Zurich Open Repository and Archive, University of Zurich

ZORA URL: https://doi.org/10.5167/uzh-161841

Journal Article

Accepted Version

Originally published at:

Franzon, Francesca; Zanini, Chiara; Rugani, Rosa (2019). Do non-verbal number systems shape grammar? Numerical cognition and Number morphology compared. Mind Language, 34(1):37-58.

DOI: https://doi.org/10.1111/mila.12183 


\title{
Do non-verbal number systems shape grammar? Numerical cognition and Number morphology compared
}

\author{
Francesca Franzon ${ }^{1,2}$, Chiara Zanini ${ }^{2,3}, \&$ Rosa Rugani ${ }^{4}$ \\ ${ }^{I}$ Neuroscience Area, International School for Advanced Studies (SISSA), Trieste, Italy \\ ${ }^{2}$ Department of Neuroscience, Università degli Studi di Padova, Padova, Italy \\ ${ }^{3}$ Universität Zürich, Romanisches Seminar, Zürich, Switzerland \\ ${ }^{4}$ Department of General Psychology, Università degli Studi di Padova, Padova, Italy
}

\begin{abstract}
Number morphology (e.g., singular vs. plural) is a part of the grammar that captures numerical information. Some languages have morphological Number values, which express few (paucal), two (dual), three (trial) and sometimes(possibly) four (quadral). Interestingly, the limit of the attested morphological Number values matches the limit of non-verbal numerical cognition. The latter is based on two systems, one estimating approximate numerosities and the other computing exact numerosities up to three or four. We compared the literature on nonverbal number systems with data on Number morphology from 218 languages. Our observations suggest that nonverbal numerical cognition is reflected as a core part of language.
\end{abstract}

\section{Keywords}

core cognition, core grammar, language typology, nonverbal number systems, number morphology

\section{Non-verbal numerical cognition}

Adult humans typically solve mathematical problems by using number words. We are so accustomed to using symbols to solve numerical tasks that it seems apparently impossible to perform mathematical calculation without the support of language. A long-debated issue concerns the existence of numerical thoughts without the words to express them; it has been proposed that number words are necessary to solve numerical problems (for a review, see Gelman \& Butterworth, 2005). However, more recent studies have shown that non-human animals (Agrillo, Miletto Petrazzini \& Bisazza, 2014; Cantlon \& Brannon, 2006; Rugani, Vallortigara \& Regolin, 2013; Vallortigara, 2012), pre-verbal infants (de Hevia, 2011; de Hevia, Izard, Coubart, Spelke \& Streri, 2014; McCrink \& Wynn, 2007) and adults who speak languages having no number words (Butterworth, Reeve, Reynolds \& Lloyd, 2008; Pica, Lemer, Izard \& Dehaene, 2004) do master numerical abilities. Moreover, educated adult humans are able to solve a subset of numerical tasks when, under specific experimental conditions, language use is prevented (Cordes, Gelman, Gallistel \& Whalen, 2001). Further evidence of language's complex relation with numbers and numerical cognition comes from double dissociations in cognitive neuropsychological case studies: aphasic language 
impairments need not implicate numerical disorders (i.e., Delazer, Girelli, Semenza \& Denes, 1999; Semenza et al., 2006; Varley, Klessinger, Romanowski \& Siegal, 2005). Likewise, cases have been described with severe numerical problems but no problem with language (i.e., Delazer \& Benke, 1997; Warrington, 1982).

Where, in the absence of language, non-verbal numerical skills (i.e., all those calculations that could be solved in absence of symbolic numerical words) are preserved, they can be compared with those of other non-linguistic organisms such as pre-verbal infants and non-human animals (Cordes et al., 2001). The similarity in performance of different species, qualitatively and quantitatively, suggests that, among the core cognitive abilities we share with other animals, there is a subset of nonverbal numerical skills, evident in human infants soon after birth, that can be considered the evolutionary foundation of more complex numerical reasoning (Cantlon \& Brannon, 2007; Dehaene, 2011; Rugani, Vallortigara \& Regolin, 2015; Spelke, 2000; Starr, Libertus \& Brannon, 2013). Non-verbal numerical cognition is thought to be based on two systems: the Object File System (OFS) and the Analogue Magnitude System (AMS). The OFS is based on the ability to individuate each new object entering a scene, to which a new file (the "object file") is assigned and stored in working memory. Perceived spatio-temporal information and property/kind changes are used to effect this. The signature of the OFS is a limit to the number (usually 3 or 4 ) of object files that can be simultaneously tracked and stored in working memory (Trick \& Pylyshyn, 1994). Differences at the upper limit, three in the case of salamanders (Plethodon cinereus; Uller, Jaeger, Guidry \& Martin, 2003), fish (Xenotoca eiseni; Stancher, Sovrano, Potrich \& Vallortigara, 2013), chicks (Gallus gallus; Rugani, Regolin \& Vallortigara, 2008, 2010, 2011; Rugani, Fontanari, Simoni, Regolin \& Vallortigara, 2009, Rugani, Cavazzana, Vallortigara \& Regolin, 2013; Rugani, Vallortigara \& Regolin, 2013, Rugani, Vallortigara \& Regolin, 2014) and frogs (Bombina orientalis, Stancher, Rugani, Regolin \& Vallortigara, 2015) and four in the case of adult monkeys (Macaca mulatta; Hauser, Carey \& Hauser, 2000), have been attributed to maturational factors (Carey, 2009). Hence, such a system is not specific to number representation, though number is implicitly represented. Quantity estimation (i.e., deciding which of two groups of objects is larger or smaller), which can involve larger numerosities, is hypothesised to be dealt with by the AMS. This system is ratio-dependent and follows Weber's law: as the ratio between the numbers to be discriminated increases, response times decrease, and accuracy increases (Gallistel \& Gelman, 1992). The minimum discernible ratio narrows over development from 1:3 for newborns, to 1:2 at 6 months, 2:3 at 9 months and 3:4 for preschool children (Feigenson, Dehaene \& Spelke, 2004; Halberda \& Feigenson, 2008; Izard, Sann, Spelke \& Streri, 2009). Dissociable neural signatures of the non-verbal numerical systems have recently been demonstrated in preverbal infants (6-7.5 months old), using event-related potentials (ERPs) while they were viewing either small (1-3) or large (8-32) sets of objects in a number alternation paradigm. Small numbers evoked a relatively early occipital-temporal response, peaking at about $400 \mathrm{~ms}$, on the absolute value of the numbers presented in successive sets, regardless of their ratio. By contrast, large numbers 
evoked a mid-latency parietal response, peaking at $500 \mathrm{~ms}$, that was dependent on the ratio between successive large numbers, irrespective of their absolute values (Hyde \& Spelke, 2011).

Until now, the relation between numerical cognition and language has been investigated mainly by considering words expressing quantities and numbers, for example, quantifiers, ordinal and cardinal numbers (i.e., Butterworth et al., 1999; Carey, 2004; Clark \& Grossman, 2007; Gelman \& Gallistel, 2004; Gordon, 2004; Lipton \& Spelke, 2003; Ochtrup et al., 2013; Pica et al., 2004; Rath et al., 2015; Salillas, Barraza \& Carreiras, 2015; Semenza, 2008; Troiani, Peelle, Clark \& Grossman, 2009). However, it has been shown that number words can dissociate neuropsychologically from other lexical categories (Bencini et al., 2011; Semenza et al., 2007). While most studies have explored this in relation to the lexicon, fewer have focussed on grammatical features (neural signature: Carreiras, Carr, Barber \& Hernández, 2010; number line [SNARC] studies: Roettger \& Domahs, 2015; developmental studies: Almoammer et al., 2013; Barner, Thalwitz, Wood, Yang \& Carey, 2007; Maruši!c, Plesni!car, Razboršek, Sullivan \& Barner, 2016; Sarnecka, Kamenskaya, Yamana, Ogura \& Yudovina, 2007).

In addition to number words, language can also encode numerosity information as Number morphology, that is, as part of the grammar. For example, in English, morphological Number values of singular and plural refer respectively to one and to more-than-one entities. The word cat has a lexical meaning of "small, usually domestic, felid" and a singular morphological Number value; the word cats has the same lexical meaning but a different Number value, namely, plural. The morphological Number value of singular is linked to a numerosity of one, while the plural refers to a numerosity different from one. A morphological system entails an opposition of two or more values: Number morphology systematically encodes different numerosities onto different values. As these values are mostly phonologically short and are mostly mandatorily expressed (Dressler, 1989), they can convey information about numerosity efficiently. Number value is mandatory for performing agreement operations, for example, in parsing phrases: compare the cat is sleeping versus the cats are sleeping.

Number morphology is widespread throughout different languages and need not be limited to oppositions such as one (singular) versus more than one (plural). In fact, some languages have morphological Number values for expressing exact numerosities up to three/four or for expressing different quantity estimations. In what follows, we illustrate the possible morphological Number values present in various languages. We propose that a parallelism exists between expressible information within Number morphology throughout natural languages and information processed by the two non-verbal numerical systems, namely, the OFS and the AMS. Furthermore, we suggest that grammar is a domain wherein Number morphology and non-verbal numerical systems interact, sharing some common evolved neurocognitive mechanisms. Speakers automatically inflect for morphological Number using quantitative and numerical information, suggesting that numerosities and magnitudes are cognitively processed whenever communicating with language. Here, we show that the 
relevance of the information about numerosity is such that the majority of languages display grammatical devices for its ready encoding and decoding.

\section{Typological data from natural languages}

Morphological Number is widespread, and very few languages lack it. The World Atlas of Language Structure database (WALS; Dryer \& Haspelmath, 2013) reports data on plurality, marking on nouns in Chapter 33A (Dryer, 2013); 90.8\% (968/1066) of reported languages encode plurality using grammatical devices. The author notes that the remaining $10 \%$ is difficult to interpret and could also mark morphological Number. Moreover, Number is marked not only on nouns and pronouns but also on verbs, referring to the numerosity of participants in an action or to the number of times or places in which an action is performed (Veselinova, 2013).

Given the extent of morphological devices marking Number across languages, Number morphology appears to be a suitable point at which to investigate the intersections between language and numerical cognition. Thus, the present study focuses on this aspect of grammar rather than on lexical means such as quantifiers (many, few...) or number words (two, ten, tenth...).

Importantly, the marking of morphological Number is subject to further constraints, mostly related to animacy and definiteness, both across and within languages. Generally, nouns tend to be marked for morphological Number values when the referent is higher in the animacy hierarchy. Dixon (1979) proposes the following hierarchy: personal pronouns > kinship terms > human nouns > animate nouns > inanimate nouns (see also Smith-Stark, 1974; for a critical discussion, see Corbett, 1996; Brown, Corbett, Fedden, Hippisley \& Marriott, 2013). For example, Malay marks Number on pronouns but not on nouns, Sarsi marks Number only for kinship terms, Manchu on pronouns and nouns denoting human beings, Comanche marks Number for animate but rarely for inanimate referents. Data from WALS reported in chapters 34A (Haspelmath, 2013) and 35A (Daniel, 2013) provide a measure of this distribution. As our survey concerns the relationship between numerical cognition and language, all the parts of speech that can refer to entities (i.e., nouns and pronouns) will be taken into consideration.

\subsection{Dataset}

The possible Number values and systems found across languages are described in the next two sections. This survey is based on data collected on a typological sample of 210 languages from 50 language families plus eight language isolates (i.e., languages that do not share genealogical relationship with other languages). Morphological Number values for each of the 218 languages are reported, for the first time, in the synoptic table in Appendix.

It is not possible to report data on all natural languages as exhaustive morphological analyses are missing for many languages. The Ethnologue catalogue, updated to 2017, lists 7,099 living languages distributed across 141 families (Simons \& Fennig, 2017). However, this number is constantly 
shifting due to the extinction of some languages and to the fact that linguists sometimes disagree in discerning which are distinct languages and which are dialects of the same language (i.e., Lewis \& Simons, 2010).

In addition, the distribution of languages within language families and users of those languages is extremely variable, which can vitiate cross-language comparisons and generalisations (Rijkhoff \& Bakker, 1998). For example, according to the Ethnologue catalogue, the Austronesian family (with 1,256 languages) and the Niger-Congo family (with 1,539 languages) comprise many related languages, while the Indo-European family lists only 446 languages. This disproportion is found even when world language distribution by area of origin and number of speakers is considered. For example, 1,313 living languages (i.e., 18.5\% of the world languages) originate in the Pacific area, which are spoken by $0.1 \%$ of the total speakers in the world. In Europe, by contrast, there are only 287 native languages (i.e., $4 \%$ of the world languages), but they are spoken by $25.8 \%$ of the total speakers (data from the Ethnologue catalogue, 2017).

This study discusses the data from the languages reported in the most exhaustive collection concerning the typology of Number (Corbett, 2000). This sample appears representative as far as language size and language family are concerned and is consistent with the most used methods of typological sampling (i.e., Dahl, 2008; Rijkhoff \& Bakker, 1998; Rijkhoff, Bakker, Hengeveld \& Kahrel, 1993).

\subsection{Possible morphological Number values ${ }^{1}$}

\subsubsection{Singular and plural: 1 versus $\neq 1$}

Singular versus plural is the basic opposition in Number morphology: 214 out of 218 languages reported in the Appendix show this opposition. If a language marks morphological Number, it shows at least the opposition in which a numerosity equal to one is encoded into a value of singular,

\footnotetext{
${ }^{1}$ An exhaustive description of all the possible morphological Number values across languages should also consider the values of general, collective and greater plural Number. A Number value of "general" expresses no information about its numerosity. An example of general number is given in Fula: besides the singular versus plural opposition, nyaarii-ru-nyaarii-ji "cat-cats," the value for general number nyaari "cat(s)" is also available when the speaker wants to refer to at least one cat without specifying if one or more. In languages that lack general Number, a similar reference may be expressed by means of singular or plural. A number value of "collective" is used to refer to a group of items considered together rather than individually. In English, the collective meaning is marked in the lexicon (i.e. "fleet" designates a group of ships); in other languages (see table), it can be expressed by morphological inflection. The value of "greater plural," sometimes called "plural of abundance" (Corbett, 2000, p.30), is used to refer to an excessive number. An example of this is taken from Banyum: the form i-sumつl means "snakes," while the form ti-sumつl refers to "an unlimited numberof snakes."
} 
while numerosities larger than one are encoded into a value of plural ${ }^{2}$. In the absence of further specification about numerosity, plural conveys the meaning of a numerosity that is interpretable as "larger than one" or, more generally, as "different from one."

\subsubsection{The values for exact numerosities of two, three, four: Dual, trial, quadral}

Some languages can denote precise numerosities up to four by means of morphological Number values of dual, trial, quadral (Corbett, 2000). At present, there is no evidence of languages that display morphology for numerosities greater than four. A precise numerosity of two is expressed by means of dual, which is quite common and attestedacross language families (84/218 languages belonging to 26/50 families have a dual). For example, in Sikuani: emairibü "a yam"-emairibü-nü “yams"- emairibü-behe "two yams" (example adapted from Aikhenvald, 2014).

A precise numerosity of three is encoded by trial. Its diffusion seems to be limited to languages in different families distributed in the Oceanic area (20/218 languages in 4/50 families), and its occurrence is restricted to pronoun inflection or constrained by the animacy of the referents. Lihir provides an example: wa "you" (singular)—go "you" (plural)—gol "you two"—gotol "you three" (Corbett, 2000).

Whether a numerosity of four can be morphologically encoded is under debate. The corresponding value of quadral seems to be found only in two Austronesian languages, namely Marshallese and Sursurunga. Moreover, its use seems to be confined to personal pronoun inflection and kinship terms (Corbett, 2000) as in Sursurunga: -i/on/ái "he/she/it"—di “they”—diar "they two"—ditul "they three"- dihat "they four".

Overall, the occurrence of values mapping exact numerosities seems to be ruled by some constraints as well: in certain languages, they can surface only on pronouns and not on nouns (as in Maori and in Ilocano) or when denoting an animate referent (as in Maltese and in Comanche).

\subsubsection{Values for a few and a few more: Paucal and greater paucal}

The morphological values that map exact numerosity do not vary across communicative conditions or with respect to their referents: a value of dual always encodes a numerosity of two. By contrast, the morphological values for approximate numerosities refer to an evaluation of the magnitude of a set of units, whose precise numerosity can be variable. Paucal is a value that refers to an estimation of a small set of entities whose numerosity is not precisely defined; in English, a concept of paucal may be expressed with the quantifier a few. For this reason, the value of paucal can refer to sets of different numerosities depending on the referential and communicative context. Thus, a certain variability

\footnotetext{
${ }^{2}$ Some modifiers can require an agreement with a Number value different from the expected one. Here, we will not consider such syntactic phenomena. Also, in languages that admit this possibility, the basic opposition of the system is the one expected between singular and plural.
} 
in the use of paucal is observed in different speakers, and even in the same speaker referring to different entities. For example, "elephant-PAUCAL may typically refer to fewer real world entities than ant-PAUCAL" (Corbett, 2000, p.40).

A morphological value for paucal occurs in geographically diverse languages and language families (30/218 languages from 9/50 families), and as distinct from trial and quadral, it is marked primarily on nouns, as in Bayso: lubán-titi "a lion"—-luban-jool "lions"—-luban-jaa "a few lions". Greater paucal is very rare, reported so far only in two Austronesian languages, Tangga and Sursurunga. Greater paucal can occur only in a language that also displays a paucal, and it is used to designate small numerosities, greater than the ones paucal would refer to (Corbett, 2000).

\subsection{Possible morphological number systems}

The term morphological Number system refers to a set of at least two morphological Number values that display a regular opposition between form and meaning in order to systematically denote different numerosities. The basic morphological Number system is singular versus plural, which is also apparent in all language families. Morphological Number values cannot emerge in a system if there is no singular versus plural opposition: the presence of the other morphological Number values (such as dual, trial, paucal) is possible only given the basic opposition singular versus plural. Beyond this basic condition, constraints concerning the values mapping exact numerosities have been known at least since Greenberg's (1963) work. Greenberg's Universal \#34 states that "No language has a trial Number unless it has a dual. No language has a dual unless it has a plural." Likewise, the presence of quadral appears to be constrained to the presence of trial. Thus, a morphological Number system can be: singular — plural—dual (e.g., Slovene, Sanskrit); singularplural—dual—trial (e.g., Ngan'gityemerri, Larike); and singular—plural—dual—trial—quadral (e.g., Sursurunga and Tangga, but see above for remarks concerning the quadral), but morphological Number systems as *singular — dual or *singular — plural — trial have not been found. Paucal is constrained only by the presence of the plural and surfaces in morphological Number systems as singular — plural—paucal (e.g., Avar, Kayapò). Systems such as singular—plural— dual—paucal (e.g., Longgu, Pilagà), in which values referring to precise and to approximate numerosities coexist, are not rare. Notably, morphological Number systems like these can show (i) a different distribution with respect to the categories of pronoun and noun and (ii) syncretism with respect to Number values. Concerning pronouns and nouns, values mapping exact numerosities tend to appear mostly on personal pronouns, while paucal tends to be marked on nouns. Few languages seem to have paucal on pronouns and not on nouns, but the question is debated (Corbett, 2000). Furthermore, in some languages, the morphological Number values mapping exact numerosities can be interpreted as a paucal value. For example, trial may be used to refer to a few entities rather than three precisely. As a consequence, morphological Number values of a system as singular-plural- 
dual — trial can alternatively be interpreted as singular — plural—dual—paucal (e.g., Larike, Murrinh - Patha); similarly, the morphological Number values of a system like that of Sursurunga can shift their interpretation to singular - plural — dual - paucal — greater paucal (the situation of Sursurunga and Tangga is still under debate). Crucially, such syncretism of morphological Number values does not take place with values of dual. As a side effect of the syncretism of values, no morphological Number system shows more than five values (Corbett, 2000) ${ }^{3}$ : all of the possible morphological Number values present across languages never occur together as a system in the same language.

Grammars are built on finite and discrete sets of elements that combine to generate a potentially infinite number of sentences. Crucially, the set of combining elements must be finite in order to be learned (as noted in mathematical learning theory, e.g., Malouf, Ackerman \& Seyfarth, 2015; Nowak, Komarova \& Niyogi, 2001) and interpreted (as noted in information theory since the pivotal work by Shannon, 1948). The amount of information within morphological systems is optimised rather than maximised by means of syncretism of Number values. Thus, different information may surface into the same morphological value (i.e., Ackerman \& Malouf, 2013; Carstairs, 1987; Loporcaro, 2011; Müller, 2007; Pirrelli \& Battista, 2000; Stump, 1991, 2006, 2010). The larger the number of morphological values in a system, the greater the amount of information encoded. A morphological Number system needs to balance the overall number of morphological Number values and the amount of information encoded. In languages that have been analysed so far, the optimised set ranges up to five values.

As a consequence of morphological syncretism, the amount of information encoded in Number morphology is less than the total amount of referential information about numerosity. For example, in languages that have a morphological Number system of singular-dual-plural, the numerosity of three cannot be encoded into a dedicated morphological value. It may be implied in the value of plural but needs additional, likely lexical, means to be unambiguously shown. In a system of singular versus plural, information about numerosities of two or three is encoded in the plural value, and thus, the reference to precise numerosities is covert.

\section{Discussion}

To date, the relation between numerical cognition and language has mainly focussed on the lexicon. Most languages have lexical words to denote precise numbers (such as ninety-nine, one hundred...), but some lack number words either completely or in part (i.e., Gordon, 2004; Pica et al., 2004). Studies have shown that speakers of such languages nevertheless master numerical tasks, supporting

\footnotetext{
${ }^{3}$ The surfacing of values of general, collective, greater plural is rather unconstrained by implications, but even in this case, the total values of the number system cannot be more than five. For example, Tigre has singular - plural - dual - paucal- general, and Katyeye has singular - plural - dual - greater plural - general.
} 
the hypothesis that number words are not essential for numerical estimations (for a review, see Gelman \& Butterworth, 2005).

We approached the relationship between numerical abilities and language from a different perspective, focusing on the information about numerosity that is encoded in the grammar (e.g., in

Number morphology). Morphological Number values can readily encode information about numerosity and are mostly mandatorily expressed. In fact, while parsing phrases, we automatically inflect words for morphological Number, taking into account the numerical information relative to the reference.

From this perspective, Number morphology offers no less insight than the lexicon in exposing relationships between language and the cognitive processing of numerosities. We have highlighted that, in addition to singular and plural values, some languages can also express quantity by means of the Number value of paucal. Moreover, some languages can express Number values referring to exact numerosities up to four: dual for two, trial for three and the debated quadral for four. Although languages may appear very different, the limits of the attested variation seem to hold for every language (Moro, 2006): this is true also in the case of Number morphology. Some Number values, such as quadral, occur less often than others across languages. However, here, the relevant point does not concern the frequency of such Number values but the possibility for them to appear in the language. It is worth noting that (i) all the possible Number values allowed across natural languages comprise the same finite set and that (ii) the highest possible exact numerosity that can be encoded in a Number value is four. So far, no spoken language has been reported to have a dedicated morphological Number value for the expression of an exact numerosity of five, six or more.

Interestingly enough, the Number values that can be encoded in noun morphology in natural languages seem to resemble the values that non-human animals and pre-verbal infants can distinguish by non-verbal number systems (see section 1). While number words can refer precisely to numerosities that are perceptually indistinguishable (such as ninety-nine vs. one hundred), we hypothesise that Number morphology encodes only numerosities and estimations that are distinguishable at the perceptual level. Thus, the estimation of quantities supported by the AMS system could be grammaticalised in the paucal versus plural or paucal versus greater paucal opposition. Similarly, numerosities processed by the OFS have their grammatical counterpart in the values of dual, trial, quadral. The value of singular is a reference to an entity: it marks the precise numerosity of "one" only in opposition to other values ${ }^{4}$. Thus, it is not always possible to trace whether the singular is used to denote a reference explicitly encoding a numerosity, a quantity or not.

At first glance, the suggested parallelism between Number encoding in morphology and the nonverbal numerical systems may not seem so straightforward. No attested morphological Number system

\footnotetext{
${ }^{4}$ For example, in most languages, nouns with a mass reference surface in the singular: as there is no opposition with the plural, it is not possible to interpret that singular as referring to a numerosity of one.
} 
entails all possible dedicated values for the encoding of information delivered by AMS and OFS processes. This may seem somewhat inconsistent with the fact that non-verbal numerical systems have been recognized as a part of the core knowledge systems. According to the core knowledge hypothesis, animals, including humans, are endowed with a small set of core knowledge systems to represent the most relevant aspects of the environment (Carey, 2009; Spelke, 2000). Core knowledge systems, therefore, represent inanimate and animate physical objects, places in the spatial layout with their geometric relationships, time and numbers (Vallortigara, Chiandetti, Rugani, Sovrano \& Regolin, 2010). As already noted (section 2.3), even when a language does not explicitly mark some core numerical information with a dedicated Number value, that does not mean that such information cannot be expressed in that language. For example, in a language without a quadral Number, the information about the numerosity of four is syncretically encoded in the value of plural, and therefore, its decoding is more generic. A language, however, may exploit other means to explicit that information-for instance, by number words. In this regard, it should be noted that any linguistic reference entails less information with respect to the entity that it denotes and that generic signs can stand for more specific signs, but not vice versa. The word dog can refer to any beagle, but the word beagle cannot refer to any dog. The same holds for morphology: a more generic value can stand for a more specific one. This is possibly why languages that mark morphological Number entail in their Number system at least the more generic values, that is, singular and plural. As the Appendix reveals, the morphological Number systems of most languages mark this basic distinction. However, this does not imply that the information about numerosity processed during language parsing is limited to that encoded in the Number value. Instead, it is likely that numerosity and magnitude information is processed by non-verbal number systems whenever a word is inflected for Number. Thus, a numerosity of two may be conceptually processed, even when the language may only permit plural marking.

In fact, evidence suggests that neural areas associated with non-verbal number processing are implicated in the processing of the most basic opposition, singular versus plural. In an fMRI study conducted by Carreiras et al. (2010), participants read noun phrases in three conditions: (a) phrases with a Gender agreement violation (i.e., *la piano "the-FEMININE piano-MASCULINE"), (b) phrases with a Number agreement violation (i.e., *los piano "the-PLURAL piano-SINGULAR") and (c) phrases with no agreement violation (el piano). The authors found increased activation in the right superior parietal gyrus and the right intraparietal sulcus for morphological Number agreement violations compared to the other two conditions. These areas are specifically associated with non-verbal numerosity processing (Dehaene, Piazza, Pinel \& Cohen, 2003; Piazza, Mechelli, Butterworth \& Price, 2002; Piazza, Mechelli, Price \& Butterworth, 2006; Piazza, Pinel, Le Bihan \& Dehaene, 2007; Pinel, Piazza, Le Bihan \& Dehaene, 2004). The authors concluded that parts of the right parietal lobe involved in non-verbal number processing are also activated during the processing of Number morphology. Thus, while grammatical processing typically activates left prefrontal cortex (e.g., Sakai, Homae \& Hashimoto, 2003), the processing of morphological Number values could require additional, number-specialised networks. While Carreiras 
et al. (2010) only explored singular/plural marking, we hypothesise that morphological Number values of dual, trial and paucal should also activate specialised number networks. The neural activation pattern could match that reported by Carreiras and colleagues or, alternatively, the networks reported to be specifically related to the two non-verbal numerical systems OFS and AMS (i.e., Hyde \& Spelke, 2011, 2012).

A further demonstration of a possible relationship between Number morphology and numerical cognition relates to the mental number line, which describes a spatial representation of numbers along a left-right-oriented continuum. Along the mental number line, small numbers are located on the left side and large ones on the right (Galton, 1880). As a result of this spatial-numerical association, adults are faster in processing small numbers when responses are executed on the left side of space and faster for large numbers when responses are executed on the right side of space. This effect is known as spatial-numerical association of response codes, SNARC (Dehaene, 2011; Fischer \& Shaki, 2014; Göbel, Shaki \& Fischer, 2011). An association between numbers and space also occurs in pre-verbal human infants (de Hevia \& Spelke, 2009) and animals (Rugani \& de Hevia, 2017; Rugani, Vallortigara, Priftis \& Regolin, 2015; Rugani, Vallortigara \& Regolin, 2015). A study by Roettger and Domahs (2015) reports a SNARC-like effect in a series of speeded behavioural response tasks using German words that varied in morphological Number. The authors found that words inflected in the singular had a relative left-hand advantage and words in the plural a relative right-hand advantage, suggesting that morphological Number impacts selectively on quantity processing. In this regard, the authors suggest that it may be useful to build paradigms using more complex morphological stimuli by exploiting languages with other morphological Number values, such as dual and paucal. Further research focussed on these fine-grained distinctions will be necessary to understand the relation between information encoded in Number morphology and those processed by non-verbal numerical cognition. We propose that Number morphology only grammaticalises information about perceptually discriminable numerosities processed by the two non-verbal numerical systems. Crucially, the non-verbal numerical systems develop early in humans and are evident across species; thus, this information seems to be highly salient from a biological perspective as a part of core knowledge systems. This capacity to encode and communicate core numerical knowledge, and more generally information processed by core knowledge systems, may reflect the salience of such information for evolutionary survival. For the first time, the present paper extends such observations to the link between Number morphology and numerical core knowledge.

Core knowledge systems can be considered cognitive tools that favour effective animal interactions within their natural environment. Recently, some of these systems have also been considered to shape the grammatical structure of human language. For example, a link has been outlined between the salience of conceiving of naïve physics, animacy and countability and the fact that these are encoded in the grammar of natural languages (Strickland, 2017; Zanini, Benavides, Lorusso \& Franzon, 2017). Furthermore, it has been proposed that the core structure of human language stems from cognitive 
processing mechanisms rather than the other way round (Christiansen \& Chater, 2008). In this regard, it has been shown that morphological systems are mastered when the amount of the encoded information is optimised rather than maximised (Kirby, Dowman \& Griffiths, 2007). This is consistent with data from associative learning theory (Wagner \& Rescorla, 1972). Because number as a real-world category is inherently structured, with smaller numerosities being implicit in larger numerosities, learning theory predicts that morphological Number hierarchy as reported in typology should emerge naturally and universally in language as a consequence of reflecting these real-life contingencies (Malouf et al., 2015). We propose that Number morphology has evolved in natural languages in order to efficiently encode information about a core cognitive feature, namely, the numerosity of entities. New research questions arise from this observation.

From the discussion above, it can be inferred that we estimate magnitudes and numerosities whenever we are selecting a pertinent morphological Number value for the words we process while parsing language. What are the cognitive and neural implications of this hypothesis? Does information coming from other non-verbal cognitive domains, such as animacy, influence our counting and/or our encoding of numerosity into grammar? We have suggested that animacy may interact with morphological Number systems as animate references are more likely to be inflected for Number (i.e., Dixon, 1979; Smith-Stark, 1974). Is this interaction cognitively based? Such observations could lead to new insightful research issues about the relation between language and cognition.

\section{References}

Ackerman, F. \& Malouf, R. (2013). Morphological organization: The low conditional entropy conjecture. Language, 89(3), 429-464.

Agrillo, C., Dadda, M. \& Bisazza, A. (2007). Quantity discrimination in female mosquitofish. Animal Cognition, 10(1), 63-70. https://doi.org/10.1007/s10071-006-0036-5

Agrillo, C., Miletto Petrazzini, M. E. \& Bisazza, A. (2014). Numerical acuity of fish is improved in the presence of moving targets, but only in the subitizing range. Animal Cognition, 17(2), 307-316.

Aikhenvald, A. Y. (2014). Number and noun categorisation: A view from north-west Amazonia. In A. Storch \& G. J. Dimmendaal (Eds.), Number - Constructions and semantics Studies in language companion (Vol. 151). Amsterdam: John Benjamins.

Almoammer, A., Sullivan, J., Donlan, C., Maruši!c, F., Žaucer, R., O'Donnell, T. \& Barner, D. (2013). Grammatical morphology as a source of early number word meanings. Proceedings of the National Academy of Sciences of the United States of America, 110(46), 18448-18453.

Barner, D., Thalwitz, D., Wood, J., Yang, S. \& Carey, S. (2007). On the relation between the acquisition of singular-plural morpho-syntax and the conceptual distinction between one and more than one.

Developmental Science, 10(3), 365-373.

Bencini, G., Pozzan, L., Bertella, L., Mori, I., Pignatti, R., Ceriani, F. \& Semenza, C. (2011). When two and too don't go together: A selective phonological deficit sparing number words. Cortex, 47(9), 1052-1062. 
Brown, D., Corbett, G. G., Fedden, S., Hippisley, A. R. \& Marriott, P. (2013). Grammatical typology and frequency analysis: Number availability and number use. Journal of Language Modelling, 1(2), 227.

Butterworth, B., Granà, A., Piazza, M., Girelli, L., Price, C. \& Skuse, D. (1999). Language and the origins of number skills: Karyotypic differences in Turner's syndrome. Brain and Language, 69, 486-488.

Butterworth, B., Reeve, R., Reynolds, F. \& Lloyd, D. (2008). Numerical thought with and without words: Evidence from indigenous Australian children. Proceedings of the National Academy of Sciences of the United States of America, 105(35), 13179-13184.

Cantlon, J. F. \& Brannon, E. M. (2006). Shared system for ordering small and large numbers in monkeys and humans. Psychological Science, 17(5), 401-406.

Cantlon, J. F. \& Brannon, E. M. (2007). Basic math in monkeys and college students. PLoS Biology, 5(12), 2912-2919.

Carey, S. (2004). Bootstrapping \& the origin of concepts. Daedalus, 133(1), 59-68.

Carey, S. (2009). The origin of concepts. Oxford: Oxford University Press.

Carreiras, M., Carr, L., Barber, H. \& Hernández, A. (2010). Where syntax meets math: Right intraparietal sulcus activation in response to grammatical number agreement violations. NeuroImage, 49(2), 1741-1749. Carstairs, A. (1987). Allomorphy in inflexion. London: Croom Helm.

Christiansen, M. H. \& Chater, N. (2008). Language as shaped by the brain. Behavioral and Brain Sciences, 31(05), 489-509.

Clark, R. \& Grossman, M. (2007). Number sense and quantifier interpretation. Topoi, 26(1), 51-62.

Corbett, G. (2000). Number. Cambridge: Cambridge University Press.

Corbett, G. G. (1996). Minor number and the plurality split. Rivista di Linguistica, 8(1), 101-122.

Cordes, S., Gelman, R., Gallistel, C. R. \& Whalen, J. (2001). Variability signatures distinguish verbal from nonverbal counting for both large and small numbers. Psychonomic Bulletin \& Review, 8(4), 698-707. Dahl, Ö. (2008). An exercise in a posteriori language sampling. Language Typology and Universals Sprachtypologie und Universalienforschung, 61(3), 208-220.

Daniel, M. (2013). Plurality in independent personal pronouns. In M. S. Dryer \& M. Haspelmath (Eds.), The world atlas of language structures online. Leipzig: Max Planck Institute for Evolutionary Anthropology.

Retrieved from http://wals.info/chapter/35

de Hevia, M. D. (2011). Sensitivity to number: Reply to Gebuis and Gevers. Cognition, 121(2), 253-255. de Hevia, M. D., Izard, V., Coubart, A., Spelke, E. S. \& Streri, A. (2014). Representations of space, time, and number in neonates. Proceedings of the National Academy of Sciences of the United States of America, 111(13), 4809-4813.

de Hevia, M. D. \& Spelke, E. S. (2009). Spontaneous mapping of number and space in adults and young children. Cognition, 110(2), 198-207.

Dehaene, S. (2011). The number sense: How the mind creates mathematics. New York, NY: Oxford University Press. 
Dehaene, S., Piazza, M., Pinel, P. \& Cohen, L. (2003). Three parietal circuits for number processing. Cognitive Neuropsychology, 20(3-6), 487-506.

Delazer, M. \& Benke, T. (1997). Arithmetic facts without meaning. Cortex, 33(4), 697-710.

Delazer, M., Girelli, L., Semenza, C. \& Denes, G. (1999). Numerical skills in aphasia. Journal of International Neuropsychological Society, 5(3), 1-9.

Dixon, R. M. W. (1979). Ergativity. Language, 55, 59-138.

Dressler, W. U. (1989). Prototypical differences between inflection and derivation. Zeitschrift für Phonetik, Sprachwissenschaft und Kommunikationsforschung, 42(1), 3-10.

Dryer, M. S. (2013). Coding of nominal plurality. In M. S. Dryer \& M. Haspelmath (Eds.), The world atlas of language structures online. Leipzig: Max Planck Institute for Evolutionary Anthropology. Retrieved from http://wals.info/chapter/33

Dryer, M. S. \& Haspelmath, M. (Eds.) (2013). The world atlas of language structures online. Leipzig: Max Planck Institute for EvolutionaryAnthropology. Retrieved from http://wals.info

Feigenson, L., Dehaene, S. \& Spelke, E. (2004). Core systems of number. Trends in Cognitive Sciences, $8(7), 307-314$.

Fischer, M. H. \& Shaki, S. (2014). Spatial associations in numerical cognition-From single digits to arithmetic. The Quarterly Journal of Experimental Psychology, 67(8), 1461-1483.

Gallistel, C. R. \& Gelman, R. (1992). Preverbal and verbal counting and computation. Cognition, 44(1), $43-$ 74.

Galton, F. (1880). Visualised numerals. Nature, 21(1980), 252-256.

Gelman, R. \& Butterworth, B. (2005). Number and language: How are they related? Trends in Cognitive Sciences, 9(1), 6-10.

Gelman, R. \& Gallistel, C. R. (2004). Language and the origin of numerical concepts. Science, 306(5695), 441-443.

Göbel, S. M., Shaki, S. \& Fischer, M. H. (2011). The cultural number line: A review of cultural and linguistic influences on the development of number processing. Journal of Cross-Cultural Psychology, 42(4), $543-565$.

Gordon, P. (2004). Numerical cognition without words: Evidence from Amazonia. Science, 306(5695), 496499.

Greenberg, J. H. (1963). Some universals of grammar with particular reference to the order of meaningful elements. In J. H. Greenberg (Ed.), Universals of language (pp. 73-113). London: MIT Press.

Halberda, J. \& Feigenson, L. (2008). Developmental change in the acuity of the "number sense": The approximate number system in 3-, 4-, 5-, and 6-year-olds and adults. Developmental Psychology, 44(5), $1457-1465$.

Haspelmath, M. (2013). Occurrence of nominal plurality. In M. S. Dryer \& M. Haspelmath (Eds.), The world atlas of language structures online. Leipzig: Max Planck Institute for Evolutionary Anthropology. Retrieved from http://wals.info/chapter/34 
Hauser, M. D., Carey, S. \& Hauser, L. B. (2000). Spontaneous number representation in semi-free-ranging rhesus monkeys. Proceedings of the Royal Society of London: Biological Sciences, 267(1445), 829-833.

Hyde, D. C. \& Spelke, E. S. (2011). Neural signatures of number processing in human infants: Evidence for two core systems underlying numerical cognition. Developmental Science, 14(2), 360-371.

Hyde, D. C. \& Spelke, E. S. (2012). Spatiotemporal dynamics of processing nonsymbolic number: An eventrelated potential source localization study. Human Brain Mapping, 33(9), 2189-2203.

Izard, V., Sann, C., Spelke, E. S. \& Streri, A. (2009). Newborn infants perceive abstract numbers.

Proceedings of the National Academy of Sciences of the United States of America, 106(25), 10382-10385.

Kirby, S., Dowman, M. \& Griffiths, T. (2007). Innateness and culture in the evolution of language.

Proceedings of the National Academy of Sciences of the United States of America, 104(12), 5241-5245.

Lewis, M. P. \& Simons, G. F. (2010). Assessing endangerment: Expanding Fishman's GIDS. Revue

Roumaine de Linguistique, 55(2), 103-120.

Lipton, J. S. \& Spelke, E. S. (2003). Origins of number sense large-number discrimination in human infants. Psychological Science, 14(5), 396-401.

Loporcaro, M. (2011). Syncretism and neutralization in the marking of romance object agreement. In M.

Maiden \& M. Goldbach (Eds.), Morphological autonomy: Perspectives from romance inflectional morphology. Oxford: Oxford University Press.

Malouf, R., Ackerman, F. \& Seyfarth, S. (2015). Explaining the number hierarchy. In Noelle, D. C., Dale, R., Warlaumont, A. S., Yoshimi, J., Matlock, T., Jennings, C. D., \& Maglio, P. P. (Eds.) Proceedings of the 37th annual meeting of the Cognitive Science Society. Austin, TX: Cognitive Science Society.

Maruši!c, F., Plesni!car, V., Razboršek, T., Sullivan, J. \& Barner, D. (2016). Does grammatical structure accelerate number word learning? Evidence from learners of dual and non-dual dialects of Slovenian. PLoS One, 11(8), e0159208.

McCrink, K. \& Wynn, K. (2007). Ratio abstraction by 6-month-old infants. Psychological Science, 18(8), $740-745$.

Moro, A. (2006). I confini di Babele. Milan, Italy: Longanesi.

Müller, G. (2007). Notes on paradigm economy. Morphology, 17(1), 1-38.

Nowak, M. A., Komarova, N. L. \& Niyogi, P. (2001). Evolution of universal grammar. Science, 291(5501), $114-118$.

Ochtrup, M. T., Rath, D., Klein, E., Krinzinger, H., Willmes, K. \& Domahs, F. (2013). Are number words fundamentally different? A qualitative analysis of aphasic errors in word and number word production. International Journal of Speech \& Language Pathology and Audiology, 1(1), 12-28.

Piazza, M., Mechelli, A., Butterworth, B. \& Price, C. J. (2002). Are subitizing and counting implemented as separate or functionally overlapping processes? NeuroImage, 15(2), 435-446.

Piazza, M., Mechelli, A., Price, C. J. \& Butterworth, B. (2006). Exact and approximate judgements of visual and auditory numerosity: An fMRI study. Brain Research, 1106(1), 177-188. 
Piazza, M., Pinel, P., Le Bihan, D. \& Dehaene, S. (2007). A magnitude code common to numerosities and number symbols in human intraparietal cortex. Neuron, 53(2), 293-305.

Pica, P., Lemer, C., Izard, V. \& Dehaene, S. (2004). Exact and approximate arithmetic in an Amazonian indigene group. Science, 306(5695), 499-503.

Pinel, P., Piazza, M., Le Bihan, D. \& Dehaene, S. (2004). Distributed and overlapping cerebral representations of number, size, and luminance during comparative judgments. Neuron, 41, 983-993. Pirrelli, V. \& Battista, M. (2000). The paradigmatic dimension of stem allomorphy in Italian verb inflection. Italian Journal of Linguistics, 12(2), 307-379.

Rath, D., Domahs, F., Dressel, K., Claros-Salinas, D., Klein, E., Willmes, K. \& Krinzinger, H. (2015). Patterns of linguistic and numerical performance in aphasia. Behavioral and Brain Functions, 11(1), 2. Rijkhoff, J. \& Bakker, D. (1998). Language sampling. Linguistic Typology, 2(3), 263-314.

Rijkhoff, J., Bakker, D., Hengeveld, K. \& Kahrel, P. (1993). A method of language sampling. Studies in Language, 17(1), 169-203.

Roettger, T. B. \& Domahs, F. (2015). Grammatical number elicits SNARC and MARC effects as a function of task demands. The Quarterly Journal of Experimental Psychology, 68(6), 1231-1248.

Rugani, R., Cavazzana, A., Vallortigara, G. \& Regolin, L. (2013). One, two, three, four, or is there something more? Numerical discrimination in day-old domestic chicks. Animal Cognition, 16(4), 557-564. Rugani, R. \& de Hevia, M. D. (2017). Number-space associations without language: Evidence from preverbal human infants and non-human animal species. Psychonomic Bulletin \& Review, 24(2), 352-369. https://doi.org/10.3758/s13423-016-1126-2

Rugani, R., Fontanari, L., Simoni, E., Regolin, L. \& Vallortigara, G. (2009). Arithmetic in newborn chicks. Proceedings of the Royal Society of London B: Biological Sciences, 276(1666), 2451-2460.

Rugani, R., Regolin, L. \& Vallortigara, G. (2008). Discrimination of small numerosities in young chicks. Journal of Experimental Psychology: Animal Behavior Processes, 34(3), 388-399.

Rugani, R., Regolin, L. \& Vallortigara, G. (2010). Imprinted numbers: Newborn chicks' sensitivity to number vs. continuous extent of objects they have been reared with. Developmental Science, 13(5), 790797.

Rugani, R., Regolin, L. \& Vallortigara, G. (2011). Summation of large numerousness by newborn chicks. Frontiers in Psychology, 2, 179. https://doi.org/10.3389/fpsyg.2011.00179

Rugani, R., Vallortigara, G., Priftis, K. \& Regolin, L. (2015). Number-space mapping in the newborn chick resembles humans' mental number line. Science, 347(6221), 534-536.

Rugani, R., Vallortigara, G. \& Regolin, L. (2013). Numerical abstraction in young domestic chicks (gallus gallus). PLoS One, 8(6), e65262. https://doi.org/10.1371/journal.pone.0065262

Rugani, R., Vallortigara, G. \& Regolin, L. (2014). From small to large. Numerical discrimination by young domestic chicks. Journal of Comparative Psychology, 128(2), 163-171. 
Rugani, R., Vallortigara, G. \& Regolin, L. (2015). At the root of the left-right asymmetries in spatialnumerical processing: From domestic chicks to human subjects. Journal of Cognitive Psychology, 27(4), 388-399.

Sakai, K. L., Homae, F. \& Hashimoto, R. (2003). Sentence processing is uniquely human. Neuroscience Research, 46(3), 273-279.

Salillas, E., Barraza, P. \& Carreiras, M. (2015). Oscillatory brain activity reveals linguistic prints in the quantity code. PLoS One, 10(4), e0121434. https://doi.org/10.1371/journal.pone.0121434

Sarnecka, B., Kamenskaya, V., Yamana, Y., Ogura, T. \& Yudovina, Y. (2007). From grammatical number to exact numbers: Early meanings of 'one', 'two', and 'three' in English, Russian, and Japanese. Cognitive Psychology, 55(2), 136-168.

Semenza, C. (2008). Number processing. In B. Stemmer \& H. Withaker (Eds.), Handbook of the neuroscience of language (pp. 219-227). Oxford: Elsevier.

Semenza, C., Bencini, G., Bertella, L., Mori, I., Pignatti, R., Ceriani, C., ... Magno Caldognetto, E. (2007). A dedicated neural mechanism for vowel selection: A case of relative vowel deficit sparing the number lexicon. Neuropsychologia, 45, 425430.

Semenza, C., Delazer, M., Bertella, L., Granà, A., Mori, I., Conti, F. M., ... Mauro, A. (2006). Is math lateralised on the same side as language? Right hemisphere aphasia and mathematical abilities. Neuroscience Letters, 406(3), 285-288.

Shannon, C. E. (1948). A mathematical theory of communication. Bell Systems Technical Journal, 27(3), 379-423.

Simons, G. F. \& Fennig, C. D. (Eds.) (2017). Ethnologue: Languages of the world (20th ed.). Dallas, TX: SIL International. Retrieved from http://www.ethnologue.com

Smith-Stark, T. C. (1974). The plurality split. In M. W. La Galy, R. A. Fox \& A. Bruck (Eds.), Papers from the tenth regional meeting, Chicago linguistic society (pp. 657-671). Chicago, IL: Chicago Linguistic Society.

Spelke, E. S. (2000). Core knowledge. American Psychologist, 55(11), 1233-1243.

Stancher, G., Rugani, R., Regolin, L. \& Vallortigara, G. (2015). Numerical discrimination by frogs

(Bombina orientalis). Animal Cognition, 18(1), 219-229.

Stancher, G., Sovrano, V. A., Potrich, D. \& Vallortigara, G. (2013). Discrimination of small quantities by fish (redtail splitfin, Xenotoca eiseni). Animal Cognition, 16(2), 307-312.

Starr, A., Libertus, M. E. \& Brannon, E. M. (2013). Number sense in infancy predicts mathematical abilities in childhood. Proceedings of the National Academy of Sciences of the United States of America, 110(45), 18116-18120.

Strickland, B. (2017). Language reflects "core" cognition: A new theory about the origin of cross-linguistic regularities. Cognitive Science, 41(1), 70-101.

Stump, G. T. (1991). A paradigm-based theory of morphosemantic mismatches. Language, 67(4), 675-725.

Stump, G. T. (2006). Heteroclisis and paradigm linkage. Language, 82(2), 279-322. 
Stump, G. T. (2010). Interactions between defectiveness and syncretism. In M. Baerman, G. G. Corbett \& D. P. Brown (Eds.), Defective paradigms: Missing forms and what they tell us (Vol. 163, pp. 181-210). Oxford: Oxford University Press.

Trick, L. M. \& Pylyshyn, Z. W. (1994). Why are small and large numbers enumerated differently? A limited-capacity preattentive stage in vision. Psychological Review, 101(1), 80-102.

Troiani, V., Peelle, J. E., Clark, R. \& Grossman, M. (2009). Is it logical to count on quantifiers? Dissociable neural networks underlying numerical and logical quantifiers. Neuropsychologia, 47(1), 104-111.

Uller, C., Jaeger, R., Guidry, G. \& Martin, C. (2003). Salamanders (Plethodon cinereus) go for more: Rudiments of number in an amphibian. Animal Cognition, 6, 105-112.

Vallortigara, G. (2012). Core knowledge of object, number, and geometry: A comparative and neural approach. Cognitive Neuropsychology, 291(1-2), 213-236. https://doi.org/10.1080/02643294.2012.654772 Vallortigara, G., Chiandetti, C., Rugani, R., Sovrano, V. A. \& Regolin, L. (2010). Animal cognition. Wiley Interdisciplinary Reviews: Cognitive Science, 1, 882-893. https://doi.org/10.1002/wcs.75

Varley, R. A., Klessinger, N. J., Romanowski, C. A. \& Siegal, M. (2005). Agrammatic but numerate. Proceedings of the National Academy of Sciences of the United States of America, 102(9), 3519-3524. Veselinova, L. N. (2013). Verbal number and suppletion. In M. S. Dryer \& M. Haspelmath (Eds.), The world atlas of language structures online. Leipzig: Max Planck Institute for Evolutionary Anthropology. Retrieved from http://wals.info/chapter/80

Wagner, A. R. \& Rescorla, R. A. (1972). Inhibition in Pavlovian conditioning: Application of a theory. In H.S. Halliday and R.A. Boakes (eds.), Inhibition and Learning, 301-336. San Diego, CA: Academic Press. Warrington, E. K. (1982). The fractionation of arithmetical skills: A single case study. The Quarterly Journal of Experimental Psychology, 34(1), 31-51.

Zanini, C., Benavides, S., Lorusso, D. \& Franzon, F. (2017). Mass is more. The conceiving of (un)countability and its encoding into language in five-year-old-children. Psychonomic Bulletin \& Review, 24(4), 1330-1340. https://doi.org/10.3758/s13423-016-1187-2 